\title{
Skeletal muscle loss in the postoperative acute phase after esophageal cancer surgery as a new prognostic factor
}

\author{
Naoaki Maeda, Yasuhiro Shirakawa* ${ }^{*}$, Shunsuke Tanabe, Kazufumi Sakurama, Kazuhiro Noma and Toshiyoshi Fujiwara
}

\begin{abstract}
Background: The postoperative survival rate of patients with esophageal squamous cell carcinoma (ESCC) remains poor compared with other gastrointestinal cancers. We hypothesized that skeletal muscle loss in the postoperative acute phase might be a new predictor for long-term prognosis after highly invasive surgery such as ESCC surgery.

Methods: The following items were retrospectively investigated. First, whether skeletal muscle loss occurred in the postoperative acute phase of ESCC was verified. Second, the preoperative and intraoperative factors involved in skeletal muscle loss in the postoperative acute phase of ESCC were investigated. Then, whether skeletal muscle loss in the postoperative acute phase affected long-term prognosis was examined. The medical records of consecutive patients who underwent radical esophagectomy for ESCC between January 2010 and February 2015 were retrospectively reviewed; 72 cases were eligible for this study. The total psoas major muscle mass index (TPI) at the level of the third lumbar vertebra (L3) was measured using computed tomography (CT) before surgery and 3 days after surgery. The long-term prognosis was estimated by the Kaplan-Meier method and the multivariate logistic regression model.
\end{abstract}

Results: There was already a significant reduction of TPI in the acute phase up to POD 3 after ESCC surgery in comparison with the preoperative baseline TPI $(P<0.001)$. The TPI reduction rate was significantly milder in cases with less blood loss during surgery and in cases that underwent thoracoscopic esophagectomy than in cases that underwent open esophagectomy. The 3-year overall survival rate was significantly different between the TPI reduction rate severe group and the TPI reduction rate mild group.

Conclusion: Skeletal muscle loss occurred even in the postoperative acute phase. Furthermore, it is very significant that skeletal muscle loss in the postoperative acute phase of ESCC surgery is involved in the long-term prognosis.

\section{Background}

Esophageal cancer is the sixth leading cause of cancerrelated mortality worldwide, and squamous cell carcinoma is a common histological type of esophageal cancer in East Asian countries [1]. Advanced esophageal cancer (ESCC) is still a clinically challenging disease that requires a trimodal approach combining surgery, chemotherapy, and radiotherapy. To achieve it, the multidisciplinary team

\footnotetext{
* Correspondence: yasuwr@md.okayama-u.ac.jp

Department of Gastroenterological Surgery, Graduate School of Medicine, Dentistry and Pharmaceutical Sciences, Okayama University, 2-5-1 Shikatacho, Kita-ku, Okayama 700-8558, Japan
}

should have expertise in pathology, radiology, endoscopy, medical oncology, surgery, nursing, dietetics, and other relevant specialists as needed. Despite the advances of multimodality therapy, radical esophagectomy (subtotal esophagectomy with two/three-field lymph node dissection) remains the mainstream treatment for advanced resectable esophageal cancers [2]. Although the surgical technique and perioperative management for ESCC have developed, the postoperative survival rate of ESCC remains poor compared with other gastrointestinal cancers

C C The Author(s). 2020 Open Access This article is licensed under a Creative Commons Attribution 4.0 International License, which permits use, sharing, adaptation, distribution and reproduction in any medium or format, as long as you give appropriate credit to the original author(s) and the source, provide a link to the Creative Commons licence, and indicate if changes were made. The images or other third party material in this article are included in the article's Creative Commons licence, unless indicated otherwise in a credit line to the material. If material is not included in the article's Creative Commons licence and your intended use is not permitted by statutory regulation or exceeds the permitted use, you will need to obtain permission directly from the copyright holder. To view a copy of this licence, visit http://creativecommons.org/licenses/by/4.0/ The Creative Commons Public Domain Dedication waiver (http://creativecommons.org/publicdomain/zero/1.0/) applies to the data made available in this article, unless otherwise stated in a credit line to the data. 
$[3,4]$. Thus, specific prediction markers for the postoperative outcomes of ESCC have been sought for the purpose of contributing to a better prognosis.

Sarcopenia was defined as the loss of skeletal muscle volume, skeletal muscle strength, and physical function in the diagnostic criteria of the European Working Group on Sarcopenia in Older People [5]. Sarcopenia is classified into primary sarcopenia and secondary sarcopenia according to its cause. Primary sarcopenia is simply caused by aging, and secondary sarcopenia is caused by activity loss (disuse), disease, or malnutrition [5].

In gastrointestinal cancers, not only the inflammation and hypercatabolism caused by the cancer itself, but also the malnutrition caused by organic changes such as a passage disorder, are likely to lead to skeletal muscle loss as a secondary sarcopenia. Furthermore, cancer treatments, including surgery, are also considered to cause skeletal muscle loss due to malnutrition, disuse, and hypercatabolism due to the side effects of their invasiveness $[6,7]$.

Recently, there have been many studies on skeletal muscle loss during the perioperative phase, including in gastrointestinal cancers. However, most analyses were of sarcopenia before surgery using the index calculated by the standard formula, and they reported that it was a risk factor for postoperative complications and a poor long-term prognosis [8-13]. Regarding skeletal muscle loss after surgery, there have been a few studies of skeletal muscle loss concerned with postoperative outcomes only in cancers of organs other than the gastrointestinal tract [14]. On the other hand, there also have been reports that body composition changes after gastrointestinal cancer surgery, such as body weight loss (BWL) and skeletal muscle loss, were greater in the postoperative acute phase (around 1 week after surgery) than in the chronic phase (about 1 or more months after surgery) [14]. In view of the above, we hypothesized that skeletal muscle loss in the postoperative acute phase might be a new predictor for long-term prognosis, especially for highly invasive surgery such as ESCC surgery. However, to the best of our knowledge, no previous study has focused on the relationship between skeletal muscle loss in the postoperative acute phase and postoperative outcomes, including long-term prognosis.

In our university hospital, routine computed tomography $(\mathrm{CT})$ has been performed on postoperative day (POD) 3 for all ESCC patients who underwent surgery to detect postoperative acute complications for more than 10 years. Thus, many CT image files of the postoperative very acute phase of ESCC patients are available in our hospital. Thus, it was possible to analyze skeletal muscle loss using them in comparison with baseline image files. In this study, the following items were retrospectively investigated. First, whether skeletal muscle loss occurred in the postoperative acute phase of ESCC was verified. Second, the preoperative and intraoperative factors involved in skeletal muscle loss in the postoperative acute phase of ESCC were investigated. Then, whether skeletal muscle loss in the postoperative acute phase affected the long-term prognosis was examined.

\section{Methods}

\section{Patients}

The medical records of consecutive patients who underwent radical esophagectomy (subtotal esophagectomy with two/three-field lymph node dissection) for ESCC at the Okayama University Hospital (Okayama, Japan) from January 2010 to February 2015 were retrospectively reviewed. A total of 273 ESCC cases without evidence of distant metastases underwent radical esophagectomy. To investigate advanced resectable ESCC, cases with clinical stage over II were selected, excluding those with T4b and supraclavicular lymph node metastasis and other organ metastasis at the time of treatment initiation. Four patients after definitive chemoradiotherapy were excluded. Nine patients with unresectable or residual cancer (R1/2) at operation were also excluded. To eliminate differences in surgical invasiveness, the operative procedure was limited to radical esophagectomy with gastric tube reconstruction; other procedures (two-stage operation, reconstruction with jejunum/colon) were excluded. Cases that underwent combined resection of other organs with cancer were also excluded. In addition, 30 cases were excluded because of insufficient CT data. Thus, 72 cases were eligible for this study (Fig. 1).

\section{Surgical procedures}

Esophagectomy with two/three-field lymph node dissection was performed. We had been performing open esophagectomy (OE) until June 2011 when thoracoscopic esophagectomy in the prone position (TEPP) was introduced. After that, we have been performing TEPP as standard procedure. In this study, 22 cases underwent $\mathrm{OE}$, and 50 cases underwent TEPP. We also investigated the relationship between those surgical procedures and skeletal muscle loss, which may be an invasive marker. Subsequently, abdominal lymphadenectomy and gastric conduit reconstruction were performed under laparotomy or hand-assisted laparoscopic surgery (HALS). The details of the surgical techniques of radical esophagectomy have been reported [15]. Data of the surgical procedure, operative time, amount of blood loss, and infusion volume were recorded as operative factors.

\section{Postoperative management}

During this period, there was no change in postoperative care, including drugs administered (methylprednisolone, antibiotics, proton pump inhibitors, catecholamine). The 


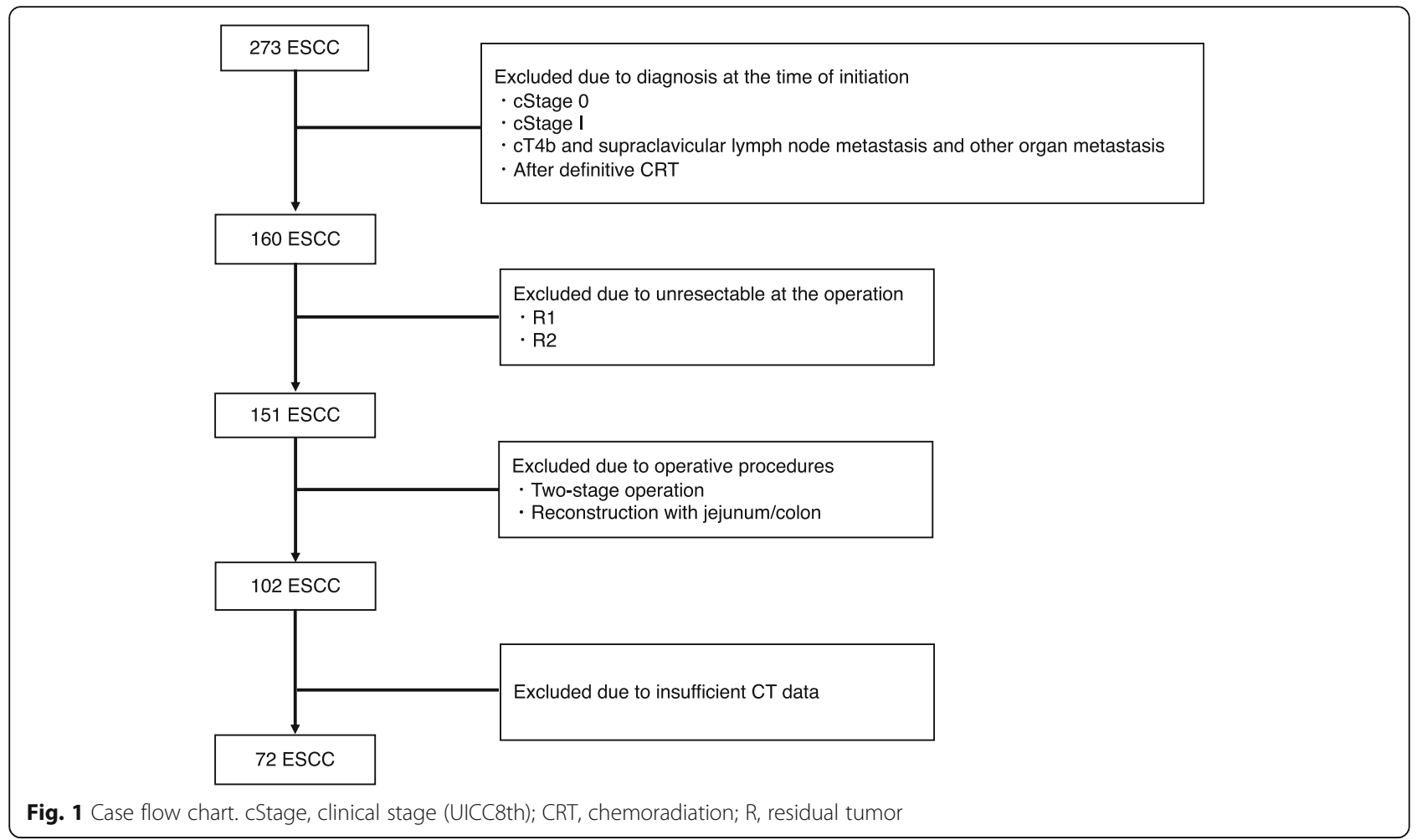

patients were admitted to the intensive care unit (ICU) on mechanical ventilation after radical esophagectomy. The patients were extubated on POD 1 if they had no problems on chest X-ray, blood examinations, and bronchoscopy. On POD 3, CT was performed to detect postoperative acute complications. If there were no serious findings on CT, and the patient's course was good, the patient could be discharged from the ICU.

\section{CT analysis}

The preoperative baseline CT examination was taken within 1 week before surgery (at the time admission for surgery) for the cases with preoperative therapy or preoperative sarcopenia and taken within 1 month before surgery for the cases without both preoperative therapy and preoperative sarcopenia. The original purpose of the $\mathrm{CT}$ examination in the postoperative acute phase (POD 3) was to detect postoperative complications such as pneumonia, anastomotic leakage, and venous thrombosis for all patients who underwent ESCC surgery. Therefore, the changes in skeletal muscle mass could be analyzed using the $\mathrm{CT}$ images of the postoperative acute phase and preoperative baseline images before surgery.

\section{Measurement of skeletal muscle loss}

Following previously published reports about sarcopenia, skeletal muscle mass was measured at the level of the third lumbar vertebra (L3) with CT images. Although there are many reports using total skeletal muscle mass at the L3 level [11, 13, 16-20], only the psoas muscle was measured to as much as possible exclude the effects of edema in the postoperative acute phase [6]. The images were evaluated using a CT image analysis system (Synapse Vincent, Fujifilm Medical, Tokyo, Japan). The iliopsoas area at the L3

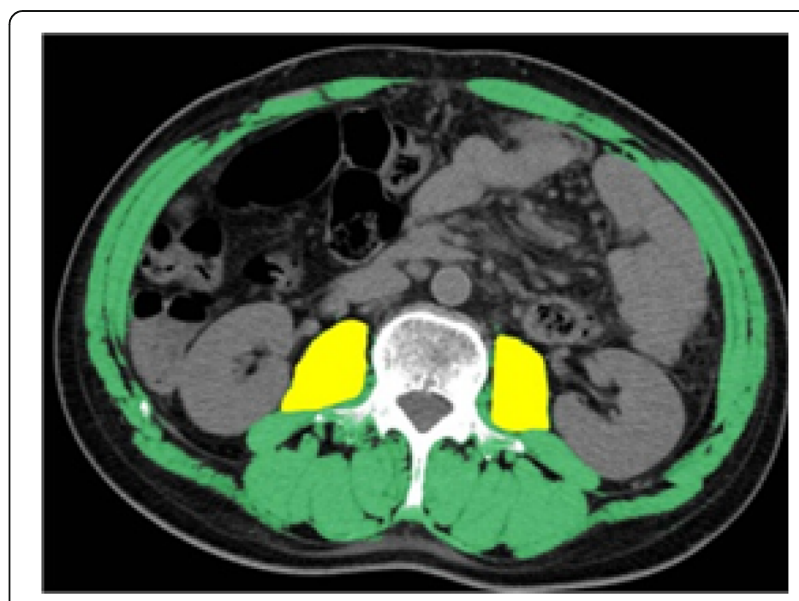

Fig. 2 Measurement of skeletal muscle mass at the level of the third lumbar vertebra (L3) with CT images. Green field, total muscle mass; yellow field, psoas muscle mass 
level was measured using Hounsfield units (HU) of 29 to +150 (Fig. 2). The quantity of skeletal muscle was evaluated with the total psoas major muscle mass index (TPI). The TPI was defined by normalizing the cross-sectional areas of the bilateral psoas major muscles for height $\left(\mathrm{cm}^{2} / \mathrm{m}^{2}\right)$. Furthermore, the change in the skeletal muscle loss from the preoperative state to the postoperative acute phase was analyzed using the change of TPI. The TPI reduction rate was calculated using the formula (postoperative TPI-preoperative TPI)/preoperative TPI $\times 100$.

\section{Analyzed parameters}

Skeletal muscle loss in the acute phase after ESCC surgery was retrospectively analyzed. For that analysis, the median TPI reduction rate was defined as the cutoff value to divide patients into the TPI reduction rate mild group and the TPI reduction rate severe group. The preoperative factors (age, blood data, tumor factors, preoperative sarcopenia, etc.) and intraoperative factors (surgical procedure, blood loss, operative time, etc.) concerned with skeletal muscle loss in the acute phase after ESCC surgery were investigated. Furthermore, the relationship between skeletal

Table 1 Patients' characteristics

\begin{tabular}{|c|c|c|}
\hline Characteristic & Number of patients (\%) $n=72$ & \\
\hline Age, y, median (IQR) & $66(43-83)$ & \\
\hline \multicolumn{3}{|l|}{ Sex, n (\%) } \\
\hline Male & $65(90 \%)$ & \\
\hline Female & $7(10 \%)$ & \\
\hline \multicolumn{3}{|l|}{ ASA, n (\%) } \\
\hline 1,2 & $65(90 \%)$ & \\
\hline$\geq 3$ & $7(10 \%)$ & \\
\hline \multicolumn{3}{|l|}{ Preoperative sarcopenia ${ }^{\mathrm{b}}, \mathrm{n}(\%)$} \\
\hline Sarcopenic & $64(89 \%)$ & \\
\hline Nonsarcopenic & $8(11 \%)$ & \\
\hline \multicolumn{3}{|l|}{ Tumor location, n (\%) } \\
\hline $\mathrm{Ce}$ & $4(6 \%)$ & \\
\hline Ut & $13(18 \%)$ & \\
\hline Mt & $30(42 \%)$ & \\
\hline Lt & $23(32 \%)$ & \\
\hline $\mathrm{Ae}$ & $2(3 \%)$ & \\
\hline \multicolumn{3}{|l|}{ Operative procedure, n (\%) } \\
\hline Open esophagectomy & $22(31 \%)$ & \\
\hline Thoracoscopic esophagectomy & $50(69 \%)$ & \\
\hline \multicolumn{3}{|l|}{ Preoperative therapy, n (\%) } \\
\hline None & $17(24 \%)$ & \\
\hline Chemotherapy & $54(75 \%)$ & \\
\hline Chemoradiotherapy & $1(1 \%)$ & \\
\hline \multicolumn{3}{|c|}{ Postoperative therapy (including adjuvant therapy), n (\%) } \\
\hline No & $22(31 \%)$ & \\
\hline Yes & $50(69 \%)$ & \\
\hline \multicolumn{3}{|l|}{ pStage, n (\%) } \\
\hline$<$ pStage III & $36(50 \%)$ & \\
\hline$\geq$ pStage III & $36(50 \%)$ & \\
\hline \multicolumn{3}{|l|}{ TPI $\left(\mathrm{cm}^{2} / \mathrm{m}^{2}\right)$, median (IQR) } \\
\hline Preoperative TPI & $4.63(3.74-5.77)$ & $P=0.116^{a}$ \\
\hline Postoperative TPI & $4.28(3.62-5.28)$ & \\
\hline
\end{tabular}

TPI total psoas major muscle mass index, pStage pathological stage (UICC 8th), ASA the American Society of Anesthesia physical status, IQR interquartile range, ${ }^{a}$ Wilcoxon rank-sum test, ${ }^{\mathrm{b}}$ According to the definition of Prado [22] 


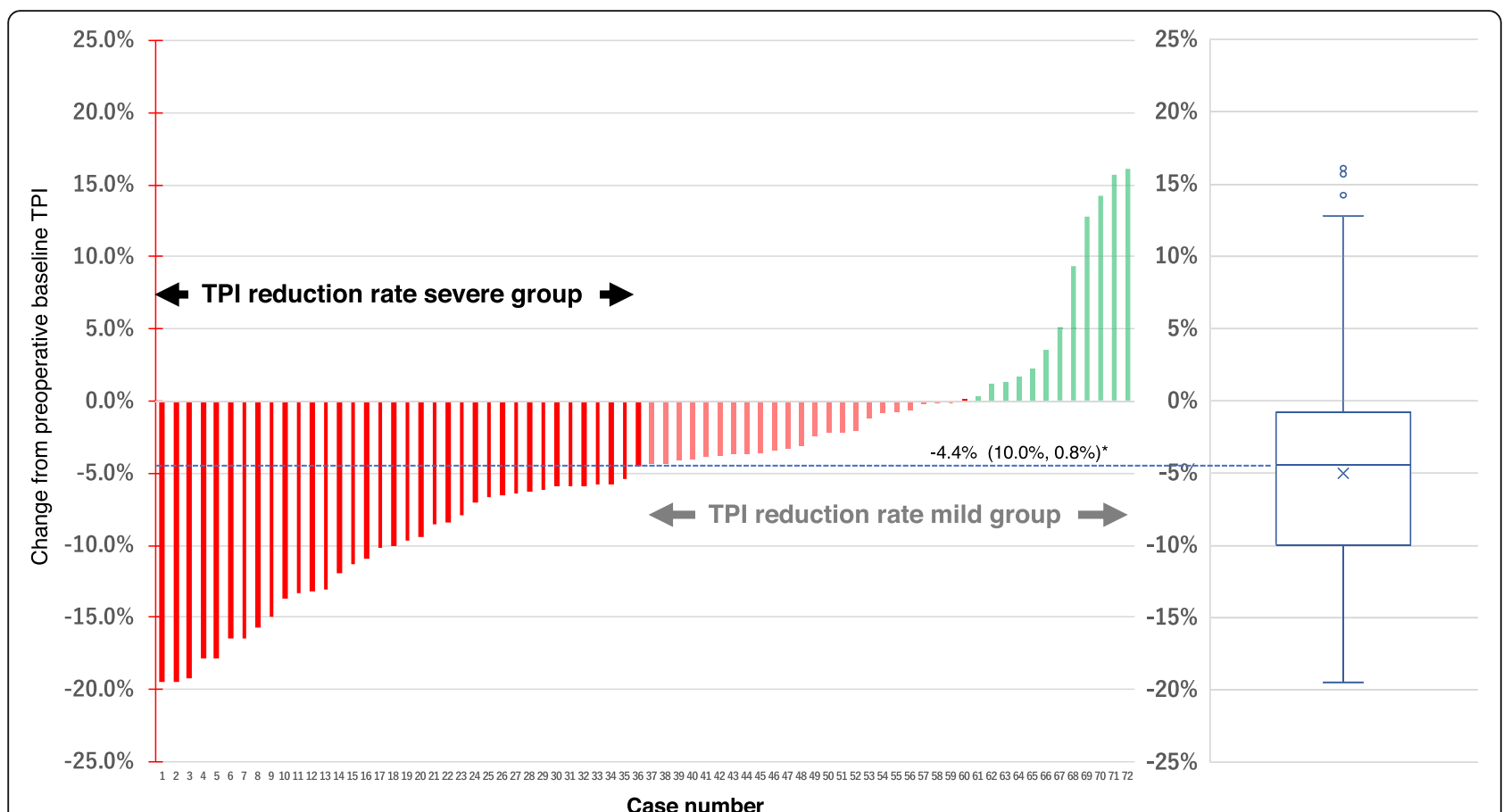

Case number

Fig. 3 Change of TPI in the acute phase after ESCC surgery from preoperative baseline TPI $(n=72)$. TPI, total psoas major muscle mass index; *median $(25 \%, 75 \%)$

muscle loss in the acute phase after ESCC surgery and long-term prognosis was investigated together with other clinicopathological parameters including preoperative sarcopenia.

\section{Statistical analysis}

Clinicopathological factors were noted according to the Union for International Cancer Control (UICC) Tumor Nodes Metastasis (TNM) Classification of Malignant Tumors, 8th edition [21]. To evaluate the differences between the two groups, continuous variables were assessed using the Wilcoxon rank-sum test, and categorical variables were evaluated using Fisher's exact test. Differences were considered significant when the $P$ value was $<0.05$. Kaplan-Meier analyses were also used to estimate the cumulative survival of patients. To identify the preoperative prognostic factors for 3 -year survival, all variables with $P<0.05$ on the univariate analysis were included in the multivariate logistic regression model. All analyses were performed using the JMP version 14 statistical analysis software (SAS Institute, Cary, NC, USA).

\section{Results}

Clinicopathological characteristics of patients with ESCC Of the 72 ESCC cases, 65 were male, and 7 were female. Physical status according to the ASA classification was grade 1 or 2 in 65 cases and grade 3 in 7 cases. The presence of preoperative sarcopenia was defined according to the standard from Prado's report [22], and the cutoff value of the skeletal muscle mass index was determined to be 52.4 for males and 38.5 for females. Patients whose values were less than or equal to the cutoff values were defined as having sarcopenia, and 64 cases were diagnosed with preoperative sarcopenia. Of the 72 cases, 55 received preoperative therapy, and 17 did not. Fifty-four cases received preoperative chemotherapy, and one case received preoperative chemoradiotherapy. The surgical procedure was $\mathrm{OE}$ with right thoracotomy in 22 cases and TEPP as minimally invasive surgery MIS in 50 cases. Half of the cases were diagnosed with pathological stage III or higher (Table 1).

\section{Change of TPI in the acute phase after ESCC surgery}

First, whether skeletal muscle loss occurred in the acute phase after ESCC surgery was examined. Out of the 72 cases, 59 cases' (81.9\%) TPI was decreased in the acute phase up to POD 3 after ESCC surgery, and the median TPI reduction rate was $-4.4 \%$. There was already a significant change in of TPI in the acute phase up to POD 3 after ESCC surgery in comparison with the preoperative baseline TPI $(P<0.001)$ (Fig. 3).

\section{Associations between patient characteristics and skeletal} muscle loss in ESCC surgery

The median TPI change rate $(-4.4 \%)$ was used as the cutoff value to divide patients into the TPI reduction rate 
mild group $(n=36)$ and the TPI reduction rate severe group $(n=36)$. The factors involved in skeletal muscle loss in the acute phase of ESCC surgery were examined. TPI reduction rate was significantly milder in cases of less blood loss during surgery $(P=0.0087)$ and in cases of TEPP than in cases of $\mathrm{OE}(P=0.0407)$ (Table 2$)$.

\section{Associations between clinicopathological factors including the TPI reduction rate and long-term survival after ESCC surgery}

The 3-year overall survival rate was significantly lower in the TPI reduction rate severe group than in the TPI reduction rate mild group $(P=0.0128)$. No significant difference between the two groups about progression-free survival (Fig. 4a, b). On the other hand, no significant difference between the two groups about with or without sarcopenia (Fig. 4c, d).
Of the patients' characteristics, surgical factors, and TPI reduction rate, the TPI reduction rate was an independent prognostic factor $(P=0.0296)$, along with pStage $(P=0.0039)$ and the presence of preoperative therapy $(P=0.0137)$ (Tables 3 and 4$)$.

\section{Discussion}

First, this study showed that skeletal muscle loss occurred in the very acute phase after ESCC surgery. Skeletal muscle loss has been known to easily occur in the postoperative period due to hypercatabolism, disuse, and malnutrition. In addition, there have been some reports of skeletal muscle loss in the postoperative relatively acute phase (7 to 10 days after surgery) in other gastrointestinal cancers [23, 24]. Even so, it was surprising that skeletal muscle loss already occurred on POD 3 after ESCC surgery.

Table 2 Correlations between characteristics and sarcopenia in patients undergoing radical esophagectomy

\begin{tabular}{|c|c|c|c|c|}
\hline Variable & Total cases & TPI reduction rate mild group & TPI reduction rate severe group & $P$ value \\
\hline Total cases, n (\%) & $72(100)$ & $36(50 \%)$ & $36(50 \%)$ & - \\
\hline Age at RE (y), median (IQR) & $66(43-83)$ & $66(55-83)$ & $66(44-82)$ & $0.9380^{\mathrm{a}}$ \\
\hline ASA, n (\%) & & & & $0.6908^{b}$ \\
\hline 1,2 & $65(90 \%)$ & 33 (92\%) & 32 (89\%) & \\
\hline$\geq 3$ & $7(10 \%)$ & $3(8 \%)$ & $4(11 \%)$ & \\
\hline Preoperative sarcopenia $^{\mathrm{d}}, \mathrm{n}(\%)$ & & & & $0.4533^{b}$ \\
\hline Sarcopenic & $64(89 \%)$ & $33(92 \%)$ & $31(86 \%)$ & \\
\hline Nonsarcopenic & $8(11 \%)$ & $3(8 \%)$ & $5(14 \%)$ & \\
\hline Tumor location, n (\%) & & & & $0.5798^{\complement}$ \\
\hline $\mathrm{Ce} / \mathrm{Ut}$ & $17(24 \%)$ & $10(28 \%)$ & $7(19 \%)$ & \\
\hline $\mathrm{Mt} / \mathrm{Lt} / \mathrm{Ae}$ & $55(76 \%)$ & $26(72 \%)$ & 29 (81\%) & \\
\hline pStage, n (\%) & & & & $0.3450^{b}$ \\
\hline$<$ pStage III & $36(50 \%)$ & $21(58 \%)$ & 15 (42\%) & \\
\hline$\geq$ pStage III & $36(50 \%)$ & $15(42 \%)$ & $21(58 \%)$ & \\
\hline Preoperative therapy, n (\%) & & & & $0.5675^{\mathrm{C}}$ \\
\hline None & 17 (24\%) & $8(22 \%)$ & $9(25 \%)$ & \\
\hline Chemotherapy & $54(75 \%)$ & $28(78 \%)$ & $26(72 \%)$ & \\
\hline Chemoradiotherapy & $1(1 \%)$ & $0(0 \%)$ & $1(3 \%)$ & \\
\hline Postoperative therapy, n (\%) & & & & $0.5675^{\mathrm{C}}$ \\
\hline None & $17(24 \%)$ & $8(22 \%)$ & $9(25 \%)$ & \\
\hline Chemotherapy & $51(75 \%)$ & $28(78 \%)$ & $26(72 \%)$ & \\
\hline Chemoradiotherapy & $1(1 \%)$ & $0(0 \%)$ & $1(3 \%)$ & \\
\hline Operative procedure, n (\%) & & & & $0.0407^{b}$ \\
\hline Open esophagectomy & $22(31 \%)$ & 7 (19\%) & $15(42 \%)$ & \\
\hline Thoracoscopic esophagectomy & $50(69 \%)$ & $29(81 \%)$ & $21(58 \%)$ & \\
\hline Blood loss (ml), median (IQR) & $330(150-510)$ & $230(110-405)$ & $370(255-723.75)$ & $0.0087^{\mathrm{a}}$ \\
\hline Operative time (min), median (IQR) & $616.5(553.5-698)$ & $622(540.75-728.5)$ & $610.5(559.25-676.5)$ & $0.4885^{\mathrm{a}}$ \\
\hline
\end{tabular}

$T P I$ total psoas major muscle mass index, RE radical esophagectomy, IQR interquartile range, ASA the American Society of Anesthesia physical status, $p S t a g e$ pathological stage (UICC 8th), ${ }^{a}$ Wilcoxon rank-sum test, ${ }^{b}$ Fisher's exact test, ${ }^{c}$ Chi-square test, ${ }^{d}$ According to the definition of Prado [22] 


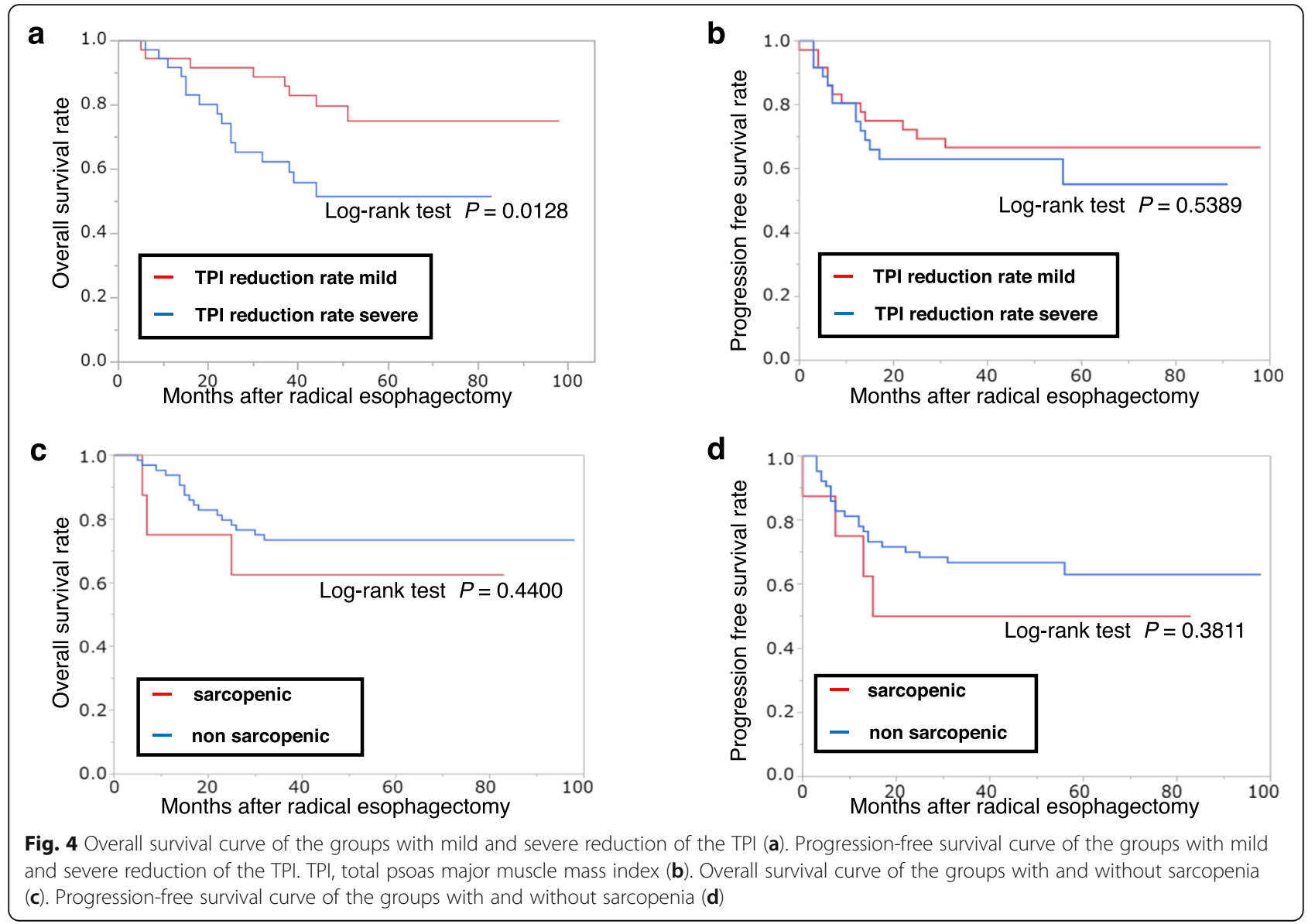

Table 3 Univariate logistic regression analysis of factors predicting overall survival in patients undergoing radical esophagectomy

\begin{tabular}{llll}
\hline Variable & P value & Odds ratio & $95 \% \mathrm{Cl}$ \\
\hline Pre-op Sarcopenia $^{\text {a }}$ & 0.5259 & 0.60 & $0.13-3.19$ \\
TPI reduction rate severe group & $0.0074^{*}$ & 4.43 & $1.47-15.3$ \\
Age $\geq 66$ y & 0.0942 & 2.57 & $0.86-8.86$ \\
$\geq$ ASA 3 & $0.0109^{*}$ & 8.33 & $1.62-62.47$ \\
Pre-op Albumin $<3.6 \mathrm{~g} / \mathrm{dL}$ & 0.7550 & 1.33 & $0.17-7.46$ \\
No preoperative therapy & $0.0492^{*}$ & 3.16 & $1.00-10.21$ \\
No postoperative therapy & 0.5367 & 0.72 & $0.25-2.03$ \\
Pre-op BMI $<18.5 \mathrm{~kg} / \mathrm{m}^{2}$ & 0.3262 & 0.47 & $0.07-2.00$ \\
Open or TEPP & 0.1053 & 2.45 & $0.83-7.33$ \\
Open or HALS & 0.2610 & 1.84 & $0.63-5.35$ \\
LN dissection field (2-field / 3-field) & 0.5692 & 1.36 & $0.48-4.15$ \\
Blood loss ( $>330 \mathrm{ml}$ ) & 0.4524 & 1.49 & $0.53-4.29$ \\
Operation time $(>616$ min) & 1.0000 & 1.0000 & $0.35-2.83$ \\
$\geq$ pStage III & $0.0012^{*}$ & 6.40 & $2.02-24.87$ \\
\hline
\end{tabular}

Pre-op preoperative, TPI total psoas major muscle mass index, ASA the American Society of Anesthesia physical status, BMI Body mass index, TEPP Thoracoscopic esophagectomy in the prone position, HALS Hand-assisted laparoscopic surgery, LN lymph node, pStage pathological stage (UICC 8th), ${ }^{a}$ According to the definition of Prado [22], * $p$ value $<0.05$ 
Table 4 Multivariate logistic regression analysis of factors predicting overall survival in patients undergoing radical esophagectomy

\begin{tabular}{llll}
\hline Variable & $P$ value (Prob > ChiSq) & Odds ratio & $95 \% \mathrm{Cl}$ \\
\hline TPI reduction rate severe group & $0.0296^{*}$ & 4.38 & $1.15-20.06$ \\
$\geq$ ASA 3 & 0.0540 & 7.62 & $0.97-92.24$ \\
No preoperative therapy & $0.0137^{*}$ & 7.07 & $1.48-42.09$ \\
$\geq$ pStage III & $0.0039^{*}$ & 7.65 & $1.86-43.05$ \\
\hline
\end{tabular}

TPI total psoas major muscle index, ASA the American Society of Anesthesia physical status, $p$ Stage Pathological stage (UICC 8 th), ${ }^{*} p$ value $<0.05$

Although the hypercatabolic phase induced by surgical invasion starts on POD 2 and lasts 3-8 days [25-28], and skeletal muscle loss due to disuse is also known to occur even after a few days of bed rest [29], malnutrition is not seen in the postoperative acute phase. Thus, it was thought that hypercatabolism and disuse might be the causes of skeletal muscle loss in that phase. According to the results of the present study, skeletal muscle loss in the postoperative acute phase might strongly reflect the hypercatabolism induced by surgical invasion because the TPI reduction rate was significantly related to intraoperative blood loss as a universal index of surgical invasion. On the other hand, the TPI reduction rate was significantly milder after TEPP than after OE. Although this might be one of the findings indicating the lesser invasiveness of TEPP, there was also another possibility: that TEPP as a painless procedure could maintain the postoperative patient's physical activity and prevent the disuse followed by skeletal muscle loss. Based on the present study, it is difficult to clarify which was the main cause, hypercatabolism or disuse, and further investigation, such as bioimpedance analysis, is needed. However, in any case, the TPI reduction rate could be a useful parameter to identify the appropriate surgery for patients, and it might be an indicator showing the advantage of TEPP. Further studies are needed to determine whether thoracoscopic surgery is more useful than open surgery in esophageal cancer, and the results of ongoing clinical research of the Japan Clinical Oncology Group (JCOG 1409) are expected to clarify this point.

The core aspect of the present study is that, to the best of our knowledge, it is the first report showing the effect of skeletal muscle loss in the acute phase after surgery on the long-term prognosis of ESCC. Although there have been some reports that perioperative skeletal muscle loss was a prognostic predictor after surgeries for cancers including ESCC $[8-14,30]$, they examined skeletal muscle loss in the preoperative phase or the postoperative chronic phase (about 1 or more months after surgery). Surprisingly, in the present study, the TPI reduction rate on POD 3 after ESCC surgery was an independent long-term predictor of prognosis that was as significant as pathological stage and neoadjuvant treatment. Thus, skeletal muscle loss, even in the acute phase, might have a certain effect on the long-term prognosis.

Therefore, in order to improve patients' prognosis after surgery for esophageal cancer, the early postoperative phase multidisciplinary team approaches, such as nutritional therapy and physical therapy, would be important to prevent skeletal muscle loss, similar to the preoperative intervention in previous reports [31-33]. On the other hand, preoperative sarcopenia was also pointed out in $89 \%$ of this study's cohort. However, it was not found to be associated with the long-term prognosis despite previously published reports [30]. The reason for it might be that most cases in this study had sarcopenia, and there was no statistical difference with the TPI reduction rate about with or without sarcopenia. Furthermore, as an operative procedure, it might be a good option to select thoracoscopic surgery from the viewpoint of skeletal muscle loss using the TPI reduction rate as a new parameter of invasiveness or disuse.

Of course, there were several limitations in this study. This was a retrospective, small cohort study conducted at a single center only with $\mathrm{CT}$ image analysis. In addition, this study recruited more males than females. In the future, a large-scale investigation adding other analytical methods is needed.

\section{Conclusion}

This is the first study that focused on the change of skeletal muscle volume between the preoperative phase and the postoperative early phase of esophageal cancer surgery. Skeletal muscle loss was an independent prognostic factor, along with pStage and the presence of preoperative therapy. It is very important that skeletal muscle loss in the postoperative acute phase was found to be related to long-term prognosis.

\section{Abbreviations}

ESCC: Esophageal squamous cell carcinoma; TPI: Total psoas major muscle mass index; BWL: Body weight loss; CT: Computed tomography;

POD: Postoperative day; OE: Open esophagectomy; TEPP: Thoracoscopic esophagectomy in the prone position; MIS: Minimally invasive surgery; HALS: Hand-assisted laparoscopic surgery; ICU: Intensive care unit; UICC: Union for International Cancer Control, TNM: Tumor Nodes Metastasis

\section{Acknowledgements}

The authors would like to thank FORTE (https://www.forte-science.co.jp/) for the English language review. 


\section{Authors' contributions}

Conception and design by NM and YS; data collected by NM and ST; establishment of study materials or enrolment of patients by $\mathrm{YS}, \mathrm{ST}, \mathrm{KN}$, and TF; data scrutiny, analysis, and clarification by NM, YS, and ST; writing and revision of the manuscript by NM, YS, and ST. Study supervision by KN, KS, and TF. All authors read and agreed with the final manuscript.

\section{Funding}

Not applicable.

\section{Availability of data and materials}

The datasets used and/or analyzed during the current study are available from the corresponding author on reasonable request.

\section{Ethics approval and consent to participate}

This study was approved by the Ethics Committee of the Okayama University Graduate School of Medicine, Dentistry and Pharmaceutical Sciences and Okayama University Hospital (approval number1906-024), and it was conducted in accordance with the ethical standards of the responsible committee on human experimentation (institutional and national) and with the Helsinki Declaration of 1964 and later versions. Due to the retrospective nature of the study, the need for informed consent was waived.

\section{Consent for publication}

Not applicable.

\section{Competing interests}

The authors declare that they have no competing interests.

Received: 8 February 2020 Accepted: 8 June 2020

Published online: 26 June 2020

\section{References}

1. Smyth EC, Lagergren J, Fitzgerald RC, Lordick F, Shah MA, Lagergren P, et al. Oesophageal cancer. Nat Rev Dis Primers. 2017:3:17048.

2. Isono K, Sato H, Nakayama K. Results of a nationwide study on the threefield lymph node dissection of esophageal cancer. Oncology. 1991;48(5): $411-20$

3. Tachimori Y, Ozawa S, Numasaki H, Ishihara R, Matsubara H, Muro K, et al. Comprehensive registry of esophageal cancer in Japan, 2012. Esophagus. 2019;16(3):221-45.

4. Ito Y, Miyashiro I, Ito H, Hosono S, Chihara D, Nakata-Yamada K, et al. Longterm survival and conditional survival of cancer patients in Japan using population-based cancer registry data. Cancer Sci. 2014;105(11):1480-6.

5. Cruz-Jentoft AJ, Baeyens JP, Bauer JM, Boirie Y, Cederholm T, Landi F, et al. Sarcopenia: European consensus on definition and diagnosis: report of the European Working Group on Sarcopenia in Older People. Age Ageing. 2010; 39(4):412-23.

6. Hanaoka M, Yasuno M, Ishiguro M, Yamauchi S, Kikuchi A, Tokura M, et al. Morphologic change of the psoas muscle as a surrogate marker of sarcopenia and predictor of complications after colorectal cancer surgery. Int J Color Dis. 2017;32(6):847-56.

7. Awad S, Tan BH, Cui H, Bhalla A, Fearon KC, Parsons SL, et al. Marked changes in body composition following neoadjuvant chemotherapy for oesophagogastric cancer. Clin Nutr. 2012:31(1):74-7.

8. Elliott JA, Doyle SL, Murphy CF, King S, Guinan EM, Beddy P, et al. Sarcopenia: prevalence, and impact on operative and oncologic outcomes in the multimodal management of locally advanced esophageal cancer. Ann Surg. 2017:266(5):822-30

9. Grotenhuis BA, Shapiro J, van Adrichem S, de Vries M, Koek M, Wijnhoven $\mathrm{BP}$, et al. Sarcopenia/muscle mass is not a prognostic factor for short- and long-term outcome after esophagectomy for cancer. World J Surg. 2016; 40(11):2698-704

10. Harada K, Ida S, Baba Y, Ishimoto T, Kosumi K, Tokunaga R, et al. Prognostic and clinical impact of sarcopenia in esophageal squamous cell carcinoma. Dis Esophagus. 2016;29(6):627-33.

11. Ida S, Watanabe M, Yoshida N, Baba Y, Umezaki N, Harada K, et al. Sarcopenia is a predictor of postoperative respiratory complications in patients with esophageal cancer. Ann Surg Oncol. 2015;22(13):4432-7.

12. Nakashima Y, Saeki H, Nakanishi R, Sugiyama M, Kurashige J, Oki E, et al. Assessment of sarcopenia as a predictor of poor outcomes after esophagectomy in elderly patients with esophageal cancer. Ann Surg. 2018; 267(6):1100-4.

13. Nishigori T, Okabe H, Tanaka E, Tsunoda S, Hisamori S, Sakai Y. Sarcopenia as a predictor of pulmonary complications after esophagectomy for thoracic esophageal cancer. J Surg Oncol. 2016;113(6):678-84.

14. Kobayashi A, Kaido T, Hamaguchi Y, Okumura S, Taura K, Hatano E, et al. Impact of postoperative changes in sarcopenic factors on outcomes after hepatectomy for hepatocellular carcinoma. J Hepatobiliary Pancreat Sci. 2016;23(1):57-64.

15. Shirakawa Y, Noma K, Maeda N, Katsube R, Tanabe S, Ohara T, et al. Assistant-based standardization of prone position thoracoscopic esophagectomy. Acta Med Okayama. 2014;68(2):111-7.

16. Miyake M, Morizawa Y, Hori S, Marugami N, Shimada K, Gotoh D, et al. Clinical impact of postoperative loss in psoas major muscle and nutrition index after radical cystectomy for patients with urothelial carcinoma of the bladder. BMC Cancer. 2017;17(1):237.

17. Mourtzakis M, Prado CM, Lieffers JR, Reiman T, McCargar LJ, Baracos VE. A practical and precise approach to quantification of body composition in cancer patients using computed tomography images acquired during routine care. Appl Physiol Nutr Metab. 2008;33(5):997-1006.

18. Psutka SP, Carrasco A, Schmit GD, Moynagh MR, Boorijan SA, Frank I, et al. Sarcopenia in patients with bladder cancer undergoing radical cystectomy: impact on cancer-specific and all-cause mortality. Cancer. 2014;120(18): 2910-8.

19. Reisinger KW, Bosmans JW, Uittenbogaart M, Alsoumali A, Poeze M, Sosef $\mathrm{MN}$, et al. Loss of skeletal muscle mass during neoadjuvant chemoradiotherapy predicts postoperative mortality in esophageal cancer surgery. Ann Surg Oncol. 2015;22(13):4445-52.

20. Sandini M, Patino M, Ferrone CR, Alvarez-Perez CA, Honselmann KC, Paiella S, et al. Association between changes in body composition and neoadjuvant treatment for pancreatic cancer. JAMA Surg. 2018;153(9):809-15.

21. Brierley JD, Gospodarowicz MK, Wittekind C. TNM classification of malignant tumors (UICC international union against cancer), 8th Ed. Oxford: WileyBlackwell; 2017.

22. Prado $C M$, Lieffers JR, McCargar $L$, Reiman $T$, Sawyer MB, Martin $L$, et al. Prevalence and clinical implications of sarcopenic obesity in patients with solid tumours of the respiratory and gastrointestinal tracts: a populationbased study. Lancet Oncol. 2008;9(7):629-35.

23. Aoyama T, Kawabe T, Hirohito F, Hayashi T, Yamada T, Tsuchida K, et al. Body composition analysis within 1 month after gastrectomy for gastric cancer. Gastric Cancer. 2016;19(2):645-50.

24. Jensen MB, Houborg KB, Norager CB, Henriksen MG, Laurberg S. Postoperative changes in fatigue, physical function and body composition: an analysis of the amalgamated data from five randomized trials on patients undergoing colorectal surgery. Color Dis. 2011;13(5):588-93.

25. Diegeler A, Doll N, Rauch T, Haberer D, Walther T, Falk V, et al. Humoral immune response during coronary artery bypass grafting: a comparison of limited approach, "off-pump" technique, and conventional cardiopulmonary bypass. Circulation. 2000:102(19 Suppl 3):lii95-li100.

26. lida Y, Yamazaki T, Arima H, Kawabe T, Yamada S. Predictors of surgeryinduced muscle proteolysis in patients undergoing cardiac surgery. J Cardiol. 2016;68(6):536-41.

27. Sander M, von Heymann C, von Dossow V, Spaethe C, Konertz WF, Jain U, et al. Increased interleukin-6 after cardiac surgery predicts infection. Anesth Analg. 2006;102(6):1623-9.

28. Tsujinaka T, Ebisui C, Fujita J, Kishibuchi M, Yano M, ., Monden M. Muscle wasting and IL-6. Basic Appl Myol 1998:8:361-370.

29. Wall BT, Dirks ML, van Loon LJ. Skeletal muscle atrophy during short-term disuse: implications for age-related sarcopenia. Ageing Res Rev. 2013;12(4): 898-906.

30. Deng HY, Zha P, Peng L, Hou L, Huang KL, Li XY. Preoperative sarcopenia is a predictor of poor prognosis of esophageal cancer after esophagectomy: a comprehensive systematic review and meta-analysis. Dis Esophagus. 2019;32:3.

31. Stephens MR, Lewis WG, Brewster AE, Lord I, Blackshaw GRJC, Hodzovic I, et al. Multidisciplinary team management is associated with improved outcomes after surgery for esophageal cancer. Dis Esophagus. 2006;19(3): $164-71$.

32. Steenhagen E, van Vulpen JK, van Hillegersberg R, May AM, Siersema PD. Nutrition in peri-operative esophageal cancer management. Expert Rev Gastroenterol Hepatol. 2017 Jul;11(7):663-72. 
33. Watanabe M, Okamura A, Toihata T, Yamashita K, Yuda M, Hayami M, et al. Recent progress in perioperative management of patients undergoing esophagectomy for esophageal cancer. Esophagus. Jul 2018;15(3):160-4.

\section{Publisher's Note}

Springer Nature remains neutral with regard to jurisdictional claims in published maps and institutional affiliations.

Ready to submit your research? Choose BMC and benefit from:

- fast, convenient online submission

- thorough peer review by experienced researchers in your field

- rapid publication on acceptance

- support for research data, including large and complex data types

- gold Open Access which fosters wider collaboration and increased citations

- maximum visibility for your research: over $100 \mathrm{M}$ website views per year

At BMC, research is always in progress.

Learn more biomedcentral.com/submissions 